\title{
O profissional de design no desenvolvimento de infográficos em jornais diários da cidade de Criciúma/SC
}

The professional of design in the development of infographics in daily newspapers of the city of Criciúma/SC

HECK, Ana Cláudia Corrêa; Bacharel; Faculdade Satc

anaheckk@gmail.com

DENARDI, Davi Frederico do Amaral; Mestre; Faculdade Satc

denardi.davi@gmail.com

\section{Resumo}

A infografia é um gênero de comunicação cada vez mais utilizado, sobretudo no jornalismo. Geralmente esse tipo de produto é de responsabilidade do designer, um profissional que nem sempre faz parte das redações jornalísticas, comprometendo a qualidade da comunicação. Assim, este estudo tem como objetivo verificar a participação do profissional do design gráfico no desenvolvimento da infografia dos principais jornais diários situados no município de Criciúma-SC por meio de entrevistas nas redações dos jornais. Como resultado percebeuse que há a falta de profissionais qualificados na área de design gráfico para a confecção de infográficos e diagramação nos jornais diários impressos.

Palavras Chave: Infografia; design; jornais.

\begin{abstract}
Infography is a type of communication that is increasingly used, especially in journalism. Usually this type of product is the responsibility of the designer, a professional who is not always part of the newsroom, compromising the quality of communication. Thus, this study aims to verify the participation of the graphic design professional in the development of the infographics of the main daily newspapers located in the city of Criciuma-SC through interviews in newsrooms. As a result it was noticed that there is the lack of qualified professionals in the area of graphic design for the making of infographics and diagramming in the daily newspapers printed.
\end{abstract}

Keywords: Infography; design; newspapers.

\section{INTRODUÇÃO}

O ritmo acelerado do cotidiano e as intensas mudanças sociais provocaram reflexos diretos na forma como as pessoas recebem e assimilam as informações. 
A difícil tarefa de prender a atenção, especialmente em se tratando de conteúdo jornalístico, deu origem a um gênero discursivo capaz de facilitar a compreensão das mensagens: o infográfico.

O infográfico, por ser composto por um conjunto de imagens ${ }^{1}$ e textos ${ }^{2}$, geralmente curtos, facilita e agiliza a transmissão de informações, fazendo com que o conteúdo seja compreendido mais facilmente, além de torna-lo mais atrativo.

O profissional responsável pela edição e criação de infográficos, é o da área do design gráfico. Este, elabora projetos gráficos, seja de maneira técnica, estética, simbólica e entre outros.

As novas tecnologias e os novos caminhos tomados pela mídia impressa evidenciaram o papel do design nos processos de comunicação e informação. Com isso, ofereceu-se aos designers um jeito novo de apresentar conteúdo. Possibilitando que a infografia fosse incorporada na prática do jornalismo. De forma ampla, trata-se de uma integração entre jornalismo e design.

Fazer jornalismo por meio do uso da infografia gera, para o leitor, mais clareza e facilidade para compreensão de temas complexos, diferente de como se fosse apenas uma notícia em forma de texto.

O infográfico, portanto, pode ser compreendido como um facilitador do entendimento da notícia, sendo um grande diferencial para meios de comunicação, como os jornais impressos, por exemplo, vistos todos os dias por milhares de pessoas.

O intuito de um jornal é ser lido, e um design bem aplicado colabora para uma boa experiência do leitor. Desta forma a participação do design gráfico faz-se necessária no desenvolvimento da informação jornalística pois utilizando de técnicas como legibilidade, leiturabilidade, organização visual e hierarquização dos elementos aplicadas à infografia, a torna mais atrativa e interessante.

O objetivo geral é verificar a participação do designer no desenvolvimento da infografia dos principais jornais situados no município de Criciúma/SC. Destacando como a presença do designer gráfico no desenvolvimento de infográficos pode contribuir para melhorar a eficiência deles.

\section{INFOGRAFIA, JORNALISMO e DESIGN}

De acordo com Teixeira (2010), foi no meio impresso, que um dos primeiros infográficos foi empregado. Segundo a autora (2010), baseado no contexto estudado de Ribeiro (2008), em abril de 1801, o jornal The Times publicou um diagrama sobre a batalha naval entre a frota inglesa e dinamarquesa, que explicava o que levou à vitória aos britânicos.

A autora (2010) ainda apresenta que outros autores, como Peltzer (1991) e Sancho (2001), defendem que o primeiro infográfico publicado foi sobre o assassinato de $\mathrm{Mr}$. Bligth's.

\footnotetext{
${ }^{1}$ Representação visual gráfica.

${ }^{2}$ Conjunto de palavras escritas.
} 
Figura 1 - Assassinato de Mr. Bligth's.

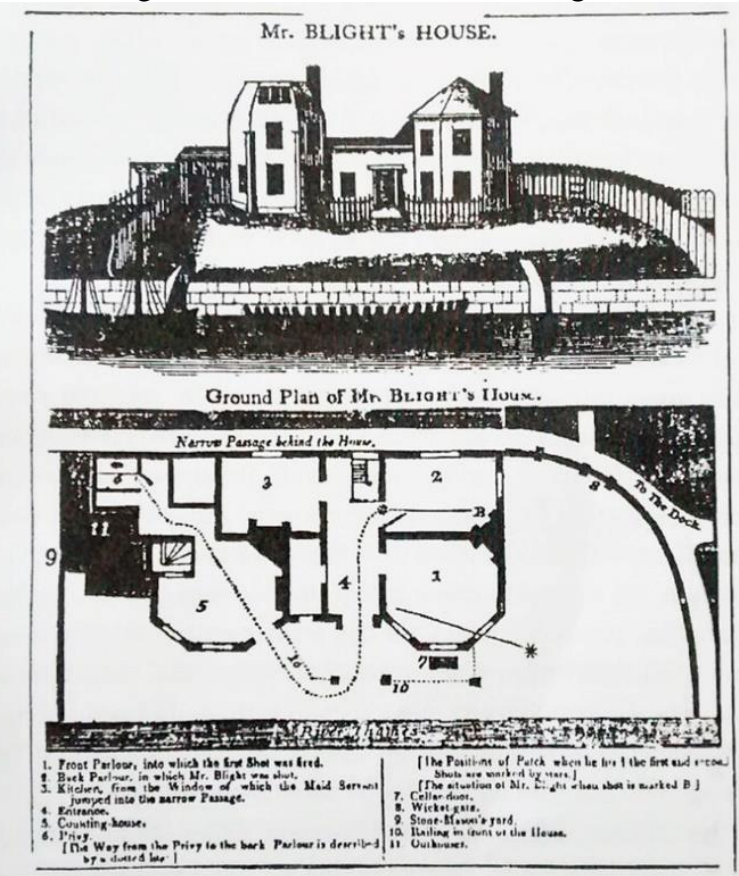

Fonte: (TEIXEIRA, 2010, p. 17)

Ele foi veiculado também no jornal The Times, mas em abril de 1806, onde a imagem (Fig. 2) explicava detalhadamente os passos do homicida, quando estava dentro da casa, o trajeto da bala que matou o Mr. Bligth's e onde ele morreu.

Hoje em dia, há muitas dúvidas ainda sobre as compreensões do termo infografia e quando, como e por que usá-lo (CECILIO; PEGORARO, 2011). O termo infográfico vem do inglês informational graphics (PEREIRA JUNIOR, 2012). E se tratando da etimologia da palavra infografia, o autor Lucena Lucas (2010) explana que info tem relação com informação e texto, grafia com desenho e ilustração.

Teixeira (2010), Maia e Pessoa (2012) discutem que infografia é a relação entre texto e imagem, ícones, gráficos, mapas, desenhos ou símbolos que constroem uma narrativa. Ele promove o melhor entendimento ao receptor da mensagem, complementa a informação, fazendo-o ter mais interesse pela notícia apresentada.

Conforme Pereira Junior (2012), o infográfico tem funções específicas quanto a sua aplicação e a sua finalidade em páginas impressas. O autor (2012) ainda comenta que de acordo com a necessidade informativa, há uso de alguns elementos na infografia como gráficos, mapas, diagramas entre outros, mas que estas maneiras de transmitir a mensagem, remete a uma confusão de significados sobre o infográfico.

O autor (2012) afirma que os mapas, como elemento na infografia, pode ajudar o leitor a entender melhor um acontecimento.

Para Pereira Junior (2012) um infográfico se torna adequado para transmitir o fácil entendimento da mensagem, devido a sua capacidade de sintetizar, dimensionar e organizar as informações ao leitor, em relação a um assunto abordado, muitas vezes, esse modelo transmite melhor o conteúdo do que um texto corrido, dados ou números. 
A maioria das apresentações infográficas geralmente é publicada juntamente com uma reportagem, dependendo da necessidade informativa, mas que não são apenas usados no jornalismo. Sobre o infográfico como narrativa jornalística, precisa obrigatoriamente seguir princípios técnicos e morais, relacionados à prática do jornalismo (TEIXEIRA, 2009).

Por fim, é possível dizer que o design e o jornalismo contribuem um com o outro para o entendimento do leitor. Baseando-se nisso, no tópico a seguir, será discutido sobre o design da infografia no meio jornalístico.

\section{Design na Infografia}

Atualmente, a infografia é vista como uma área pertencente ao design gráfico, pelo fato de o design da informação estar diretamente relacionado com a comunicação, com o objetivo de otimizar o processo de comunicar. Decorrente disso, o infográfico expõe de forma mais sucinta e direta do que conteúdos informacionais descritivos (LIMA, 2015; NOGUEIRA; NOJIMA; BRAIDA, 2015)

O designer ou designer de informação é o profissional responsável pelo projeto gráficovisual na confecção de um infográfico. Segundo Lima (2015), é ele quem atua na transformação da informação adequando-a a contextos sociais diferentes.

Nogueira, Nojima e Braida (2015, p. 04) complementam conceituando o desigger como o "projetista de um discurso visual que fará a transição do discurso editorial ao leitor", ou seja, o papel desse profissional é o de construir significados para as mensagens que serão representadas.

Módolo (2007) afirma que através de um design bem definido de infográficos permitese um melhor aproveitamento do espaço da página. O designer é o profissional capaz de reduzir e tornar a informação simples, com uma linguagem visual que atraia o público, fazendo com que a mensagem se torne mais acessível ao público-alvo.

A autora (2007) afirma que este mesmo público é quem necessita ler mais em menor tempo, por isso, quando os fatos mostrados visualmente, são aprovados positivamente, pois o leitor entende melhor e mais rápido. Ela ainda afirma que a informação visual está tão presente que não se pode mais ignorá-la.

Para tanto, o designer que atua nos jornais usa fontes de texto, fontes de título, fotografias, desenho a traço, entre outros elementos gráficos. O infográfico exige a utilização destes e usa, principalmente, as cores. (MÓDOLO, 2007). Em um projeto gráfico, o tipo tipográfico é tratado com a mesma importância visual e, às vezes, é considerado até mais relevante que um desenho ou uma foto (SUZIGAN, 2012).

Mark Porter, ex diretor de criação do The Guardian ${ }^{3}$, afirma que a maioria das páginas de um jornal não são diagramada por designers, o que implica na substituição por outro profissional, muitas vezes não qualificado. (CALDWELL; ZAPPATERRA, 2014).

A utilização da infografia se torna precária em jornais de médio e pequeno porte por causa dessa falta de um designer, ou pelo fato do único profissional especializado na área ter que atender a todas as demandas do jornal.

Já em jornais de grande porte, existem departamentos específicos para o desenvolvimento de infográficos. Dessa forma a elaboração dos infográficos é mais efetiva em decorrência da interação entre os profissionais do jornalismo e do design gráfico. Assim, faz com que a infografia esteja mais presente nos veículos de comunicação desse porte. Por

${ }^{3}$ Jornal Britânico fundado em 1821.

6o GAMPI Plural, 2017, Joinville, SC. 
ora, o infográfico acaba por facilitar a compreensão da notícia e o que por consequência, melhora o envolvimento com seu público-alvo (CECILIO; PEGORARO, 2011).

Conforme o que foi apresentado anteriormente no estudo desta pesquisa. A infografia tem se tornado um grande diferencial para meios de comunicação, como os jornais impressos. Por ser composto por um conjunto de imagens e textos, cujo principal objetivo gira em torno de facilitar e agilizar a transmissão de informações. Gera para o leitor mais clareza e facilidade na compreensão de temas complexos, bem como torna o conteúdo mais atrativo.

Assim, é possível dizer que o design é o responsável pelo projeto gráfico-visual de um infográfico, que tem como objetivo principal persuadir o leitor a quem será destinado. Entretanto, para essa funcionalidade do infográfico se fazer válida, a participação do design gráfico faz-se necessária. Por estar relacionado a técnicas como legibilidade, leiturabilidade, organização visual e hierarquização dos elementos, o que fica evidente que o design gráfico vai além de uma organização simples de textos e imagens.

Por fim, o objetivo desta pesquisa tem como finalidade verificar a participação do designer no desenvolvimento da infografia dos principais jornais situados no município de Criciúma/SC. Destacando como a presença do designer gráfico no desenvolvimento de infográficos pode contribuir para melhorar a eficiência deles.

\section{PROCEDIMENTOS METODOLÓGICOS}

O presente estudo utilizou como ferramenta de levantamento dos dados a elaboração de uma entrevista que, segundo Marconi e Lakatos (2004, p. 196) "tem como objetivo principal a obtenção de informações do entrevistado, sobre determinado assunto ou problema".

A pesquisa foi realizada em quatro jornais diários da cidade de Criciúma/SC, cadastrados na Associação dos Diários do Interior de Santa Catarina (ADI) ${ }^{4}$, no Instituto Verificador de Comunicação (IVC) ${ }^{5}$ e indicados como referência ao longo das entrevistas. Assim, dois jornais foram identificados no site da ADI, um no IVC e um por indicação dos entrevistados.

A fim de verificar a participação do designer no desenvolvimento de infográficos nos jornais diários de Criciúma-SC, a entrevista semiestruturada foi realizada com editores chefes, por serem os responsáveis por coordenar todas as etapas da produção e edição do jornal. E os diagramadores, pois são quem distribuem os elementos gráficos nas páginas impressas do jornal.

Segundo Gil (2008), a preparação do roteiro das entrevistas deve ser elaborada com clareza, de forma que não gere dúvidas ao entrevistado. Portanto, para este estudo foi desenvolvido um roteiro de entrevista (descritas abaixo) composto por oito perguntas, onde cada pergunta foi elaborada de acordo com o que foi exposto no capítulo de fundamentação teórica deste.

A pergunta um teve como propósito conhecer o entrevistado, afim de saber qual cargo este exerce no jornal, para ser o iniciador da entrevista.

1 - Nome, idade, formação, cargo no jornal e tempo no atual cargo e tempo de experiência na área.

A número dois teve como propósito descobrir o que é de fato um infográfico para o entrevistado, se ele conhece o termo.

\footnotetext{
${ }^{4}$ http://www.adisc.com.br/site/diarios.php

${ }^{5}$ http://www.ivcbrasil.org.br/
} 
2 - Você já ouviu falar sobre infográficos? Se sim, o que você entende sobre. (Dê uma breve explicação)

A questão três quis desvendar se há o uso diários de infográficos nos jornais da cidade ou se o uso é usado apenas em matérias tratadas como "especiais" de um período de prazo maior. E caso não seja usado, ter o porquê que ele não é desenvolvido, já que segundo a fundamentação teórica (TEIXEIRA, 2010; MAIA; PESSOA, 2012; PEREIRA JUNIOR, 2012) o uso de infográficos ajuda a transmitir a mensagem com fácil entendimento.

3 - No jornal em que trabalha, a infografia é constantemente presente nas matérias? Se sim, em que tipos de matérias eles são desenvolvidos? Se não, porque não é confeccionado?

A questão a seguir procurou verificar se o uso de infográficos tem efeito positivo na recepção da matéria, ou seja, se os entrevistados têm um feedback sobre o uso desse tipo de recurso.

4 - Qual o seu ponto de vista, sobre o uso deste tipo de recurso?

A número cinco teve como propósito descobrir quem é o profissional responsável pela área nos jornais da cidade, e se este profissional que executa tem alguma formação acadêmica, como discutido na fundamentação teórica, sobre a maioria das páginas de um jornal não serem diagramadas por designers formados (CALDWELL; ZAPPATERRA, 2014).

5 - Hoje em dia qual profissional é responsável pela diagramação do jornal? E quem faz os infográficos quando solicitado? Esse profissional tem alguma formação ou especialização no assunto?

A número seis buscou os assuntos tratados no capítulo "Design na infografia", sobre a relação do profissional de design e jornalismo (CALDWELL; ZAPPATERRA, 2014; CECILIO; PEGORARO, 2011). Afim de saber qual o tipo de participação de ambos na elaboração dos infográficos nos jornais regionais, e se há um bom relacionamento.

6 - Como atuam o designer e o jornalista ao longo do processo de edição?

Ainda sobre a relação das duas profissões a questão número sete teve como propósito descobrir se nesta relação a comunicação de ambos é positiva.

7 - Como é feito o pedido da confecção de infográficos ao responsável? Existe alguma formalização desse processo, como reunião ou documento (mesmo que manuscrito)?

A pergunta número oito, teve como proposito saber quais concorrentes diretos os jornais entrevistados tem na cidade de Criciúma, para serem possíveis entrevistas.

8 - Cite os jornais diários que você considera concorrentes diretos do seu, na cidade de Criciúma.

As entrevistas foram realizadas no período de 22 a 29 de setembro de 2016, onde foram coletadas um total de oito respostas. Em um primeiro momento os jornais foram contatados por telefone. Posteriormente foi enviado por e-mail um convite, formalizando a participação e agendamento da entrevista, aos editores-chefes e diagramadores. Dentre os jornais apenas um não se obteve retorno aos telefonemas e nem e-mails. Foram entrevistados quatro diagramadores e quatro editores-chefes, sendo duas mulheres e seis homens.

Os diagramadores tinham entre 29 a 48 anos, tendo tempo no atual cargo entre um a 14 anos e cinco a 18 anos de tempo de experiência na área. Nenhum com alguma formação, apenas conhecimentos em programas como pacote adobe.

Os editores-chefes tinham entre 27 e 37 anos, todos jornalistas formados, com tempo no atual cargo entre três meses a três anos e um tempo de experiência na área de seis a 16 anos. As entrevistas foram realizadas individualmente e com permissão do entrevistado elas foram gravadas. 
De acordo com a pesquisa, a questão número oito onde eram perguntados sobre os concorrentes. Notou-se que um jornal que não se obteve no levantamento inicial, foi citado pelos entrevistados, gerando assim mais um veículo para entrevistas, que já foi incluso anteriormente nos dados apresentados.

$\mathrm{Na}$ sequência, serão apresentadas através desta metodologia de análises os resultados e discussões dos dados obtidos por meio da entrevista utilizada como ferramenta de coleta.

\section{Análise e discussão dos dados}

Este capítulo traz as análises e discussões sobre os resultados dos dados obtidos na entrevista que teve como objetivo verificar a participação do designer no desenvolvimento da infografia dos principais jornais situados no município de Criciúma/SC. Destacando como a presença do designer gráfico no desenvolvimento de infográficos pode contribuir para melhorar a eficiência deles.

Para o melhor entendimento deste estudo, a análise foi feita por meio de um relato a partir das respostas das oito perguntas, onde cada resposta será discutida separadamente, corroborando com o fundamental teórico discutidos e apresentados anteriormente.

A primeira questão abordava sobre o conhecimento dos entrevistados por infográficos. Se eles já tinham escutado falar sobre, e poderiam dar uma breve explicação sobre este termo.

Notou-se que sete dos oito entrevistados, conheciam ou já ouviram falar sobre, mas quando pedido para dar um entendimento sobre o termo, ainda se obtinha dúvidas dos entrevistados, que ficavam confusos ao falar.

Dois dos quatro editores-chefes, e dois dos quatro diagramadores entrevistados enfatizaram o infográfico como uma forma de atrair o leitor e facilitar o entendimento da mensagem a ser transmitida, o que resultou na corroboração da base teórica deste estudo, segundo os autores, Coelho (2008), Pereira Junior (2012), Teixeira (2010) e Maia e Pessoa (2012).

Para os outros dois editores-chefes, seria uma maneira de "organizar informações, dentro de alguma coisa gráfica. Seja uma tabela, ou qualquer número, ou passar a informação de forma gráfica", explica o editor 3.

O diagramador 4 citou que talvez não conhecesse por essa nomenclatura, mas que acreditava em ser "a informação com base no fundamento visual”. Já para o diagramador 2, seria uma forma de apresentar dados específicos, como numerações, principalmente em pesquisas percentuais de candidatos ou pesquisas do IBGE. Segundo a fundamentação teórica deste estudo, pode-se esclarecer que a infografia não se remete apenas a dados estatísticos ou numéricos, mas também como apresentam os autores Teixeira (2010), Maia e Pessoa (2012) é a relação entre texto e imagem, ícones, gráficos, mapas, desenhos ou símbolos que constroem uma narrativa.

De acordo com as concepções apresentadas, observa-se que entre os entrevistados há um conhecimento superficial sobre o tema estudado. O que pode resultar no uso superficial da infografia nos jornais diários da cidade e muitas vezes a falta deste recurso nas edições.

Dando sequência para a entrevista, a pergunta número dois questionava sobre essa presença de infográficos nos jornais em que trabalhavam. Em que tipo de matérias eram empregados e se não havia, porque não eram confeccionados. Essa pergunta teve como finalidade desvendar os motivos pelo uso deste recurso, por uma vez que os autores da fundamentação teórica corroboram que o uso de infográficos ajuda a transmitir a mensagem com fácil entendimento. 
Todos os entrevistados afirmaram ter a presença de infográficos nas edições dos jornais. Mas de acordo com o editor 1 e o diagramador 1, é usado, mas não com tanta frequência, devido à falta de disponibilidade de espaço no jornal, e o pouco tempo de produção, devido a serem jornais diários.

De acordo com o editor 3, o infográfico é mais usado em matérias especiais, pois são matérias que não são do dia-a-dia, não factuais, que exigem mais tempo para confeccioná-las, e que exigem um grau de informação maior. Devido a esta resposta, pode-se supor que a ausência de um profissional responsável pela infografia está diretamente ligada a ausência de infográficos na maioria das edições diárias, uma vez que provavelmente designers tenham maior familiaridade com elementos de estruturação da comunicação visual e assim consigam desenvolver infográficos com rapidez e qualidade.

Sobre as matérias em que são mais utilizadas, obteve-se como resposta entre sete dos oito entrevistados que as matérias de economia e política são as que eles procuram usar mais o infográfico quando conseguem, pois, são matérias que geralmente apresentam dados numéricos, tabelas e gráficos, gerando assim maior clareza ao leitor.

A partir desta resposta é perceptível a afirmação de Pereira Junior (2012) que de acordo com a necessidade informativa há uso de alguns elementos na infografia como gráficos, mapas, diagramas entre outros, mas que estas maneiras de transmitir a mensagem, remete a uma confusão de significados sobre o infográfico.

Novamente fica evidente que as respostas dos entrevistados foram sucintas de acordo com a abrangência que o tipo de recurso oferece, pois focalizaram no uso de infográfico apenas como sendo a representação gráfica de numerais.

$\mathrm{Na}$ terceira questão da entrevista, foi abordado sobre o ponto de vista do entrevistado, sobre este tipo de recurso. Retomando sobre a importância do uso de infográficos nas edições impressas.

Todos os entrevistados deram uma resposta positiva, e afirmaram que deveria ser adotado frequentemente nos jornais diários, por agregar valor e chamar a atenção para a leitura. Segundo o diagramador 3 o infográfico deixa o jornal mais bonito, mais atrativo, e as páginas mais leves. Com base nesta resposta, é possível verificar o que Módolo (2015) diz sobre o design, quando utilizado alguns recursos gráficos como: cores, desenhos, tabelas entre outros, chamam a atenção do leitor e informa de forma atrativa.

Com isso, têm-se a importância de um profissional especializado em design, pelo conhecimento que este tem na área. Esta afirmação corrobora com o que foi apresentado anteriormente sobre a área do design estar relacionada com a comunicação, e que o designer em um meio jornalístico pode fazer uma contribuição importante para a dinâmica da redação.

Para confirmar as concepções apresentadas até o momento, a pergunta número quatro teve como finalidade descobrir qual o profissional que é responsável pela diagramação do jornal e quem faz os infográficos.

De acordo com os resultados encontrados durante a entrevista, notou-se que os diagramadores, que são os responsáveis pelo design das páginas do jornal, também são os que desenvolvem os infográficos. Estes profissionais não são graduados em design, mas são especializados em ferramentas como softwares de editoração eletrônica, e entre cinco a 18 anos de tempo de experiência na área. Conforme o editor 3, também em algumas edições o próprio repórter que fez a matéria é quem faz o infográfico. 
Portanto, pode-se afirmar que a infografia não se faz presente nas edições diárias do sul de Santa Catarina, e que isso pode ser fruto da pela falta de um profissional de design o que pode limitar os recursos disponíveis a serem usados para facilitar o entendimento do leitor.

A questão número cinco quis saber qual era a relação do jornalista e o designer/diagramador e como ambos operavam no jornal. Todas as entrevistas tiveram uma resposta positiva, quanto a relação entre eles. O diagramador 1,3 e 4 enfatizam que é uma relação de troca e muita parceria. $\mathrm{O}$ editor 2 corrobora dizendo que essa relação "dá muito certo", tanto que o departamento trabalha lado-a-lado literalmente, trocando informações e se ajudando, conta. As respostas dos entrevistados confirmam a necessidade de uma relação de parceria e de se trabalhar em equipe, entre o jornalismo e o design, tanto para a produção de um infográfico quanto na edição do jornal, conforme afirma Texeira (2010).

Na pergunta seis, foi questionado como era feito o pedido de confecção de infográficos, se havia alguma formalização desse pedido. Segundo a resposta de todos os entrevistados não há nenhum tipo de documento formalizado. Os diagramadores explicam, que recebem as informações escritas. O diagramador 2, conta que quando há algum pedido mais elaborado, como é o caso do infográfico o próprio repórter já tem a ideia de como quer, então acontece de o repórter sentar do lado do diagramador, e ter uma conversa, mas nada muito formalizado.

As respostas acima sugerem que apesar da relação de complementaridade entre jornalista e designer/diagramador, nos jornais diários do sul de Santa Catarina que participaram do presente estudo é o jornalista que assume a responsabilidade e a iniciativa do desenvolvimento de infográficos. Isso implica em uma redução das potencialidades do uso da infografia como gênero, já que o jornalista a princípio não possui a mesma capacidade de comunicar visualmente que um designer tem.

$\mathrm{Na}$ questão número sete, foi perguntado sobre o tempo de pedido desse material, e se nas matérias especiais, que são elaboradas com um pouco mais de antecedência, não factuais, se havia um tempo maior para a confecção de infográficos, se era pensado no desenvolvimento deste.

$\mathrm{O}$ editor 1 conta que normalmente é pedido com antecedência apenas em matérias especiais, que não são factuais, e há um tempo maior de elaboração. Mas que na maioria das vezes o pedido é feito com algumas horas antes de fazer o fechamento para a gráfica, não havendo um tempo tão grande para o desenvolvimento, por falta de profissionais. $\mathrm{O}$ editor 1 lembra, que por conta de falta de profissionais o diagramador não tem muito tempo para diagramar. Por ser o único responsável pelo fechamento do jornal completo, faz com que ele acabe dividindo sua atenção com todas as outras matérias. Com isso, se tem a afirmação dos autores Cecilio e Pegoraro (2011) que esse desenvolvimento dos infográficos se tornam precários em jornais de pequeno porte, por terem apenas um único responsável pela diagramação, e não haver um tempo hábil para a confecção.

Para finalizar a entrevista, a pergunta número oito, teve como propósito saber se havia algum outro tipo de veículo que não citados nos sites de registros sobre os cadernos diários. Notou-se que entre os que estavam registados, havia um que era considerado concorrente direto dos jornais entrevistados. Sendo assim, as entrevistas foram realizadas neste jornal comentado na entrevista. Conforme o que foi apresentado anteriormente, este veículo de informação citado, já está incluso na análise de resultados. 


\section{Conclusão}

Esta pesquisa teve como objetivo geral verificar a participação do designer no desenvolvimento da infografia dos principais jornais situados no município de Criciúma/SC. Destacando como a presença do designer gráfico no desenvolvimento de infográficos pode contribuir para melhorar a eficiência deles.

Referente ao que foi apresentado neste estudo, o infográfico por ter um apelo visual, tem como função despertar o interesse na leitura. Neste caso, despertar o interesse pela leitura das matérias dos jornais diários impressos e já que os infográficos oferecerem mais facilidade nos conteúdos jornalísticos, evidencia-se o papel do designer nos processos de desenvolvimento da informação e comunicação.

Com base na pesquisa e nas respostas dos entrevistados, pode-se observar que há a falta de profissionais qualificados na área de design gráfico para a confecção de infográficos e diagramação nos jornais diários impressos.

Para os autores, o uso da infografia podem comunicar de forma mais eficiente as notícias e atrai o público-alvo a quem se dirige o jornal. Durante a pesquisa ficou evidente a dificuldade de encontrar nestes veículos a presença do uso deste recurso. Devido à análise feita, obtém-se como resposta à falta de tempo para a elaboração destes e também pela falta de espaço disponibilizados.

Como alternativas para melhoria deste serviço nos jornais, os autores sugerem a contratação de um profissional qualificado na área de design gráfico. Para atender a demanda de diagramação e desenvolvimento dos infográficos nas redações dos jornais. Até mesmo a contratação de uma empresa terceirizada para atender os jornais, como estúdios de design, ou a contratação de designers freelancers.

Sendo que os jornais da região seguem um projeto gráfico, os autores sugerem como outra alternativa, que seja refeito ou adaptado o projeto gráfico para que o desenvolvimento de infográficos seja realizado por diagramadores, adaptando-se a correria do dia-a-dia que os jornais têm.

Deve-se lembrar que este projeto gráfico, deve ser desenvolvido por profissionais de design, por serem os especialistas na área. E pelo fato, de o designer, segundo este estudo, ser o profissional que resolve problemas relacionados à comunicação.

\section{Referências}

CALDWELL, Cath. ZAPPATERRA, Yolanda. Design Editorial: Jornais e Revistas / Mídias Impressas e Digitais. 1 ed. São Paulo: Gustavo Gili, 2014.

CECILIO, Evane e PEGORARO, Everly. A infografia no jornalismo impresso: além da simples complementação, um novo modo de se fazer jornalismo. 2011. VIII Encontro Nacional de História da Mídia Unicentro, Guarapuava, PR, 2011.

GIL, Antonio Carlos. Como elaborar projetos de pesquisa. São Paulo, v. 5, n. 61, p. 16-17, 2008.

LIMA, Ricardo Cunha. O que é infografia jornalística?. Revista Brasileira de Design da Informação/Brazilian Journal of Information Design. São Paulo, v. 12, n. 1. 2015, p. 111 - 
127.

LUCAS LUCENA, Ricardo Jorge de. Infografia Jornalística: uma revisão bibliográfica necessária. X Congreso de ALAIC: 2010.

MARCONI, M. de A.; LAKATOS, Eva Maria. Metodologia científica. São Paulo: Atlas, 2004.

MÓDOLO, Cristiane Machado. Infográficos: características, conceitos e princípios básicos. Unesp, 2007.

NOGUEIRA, Daniel; NOJIMA,Vera Lucia; BRAIDA, Frederico. 2015. Retórica do design: discurso visual e persuasão na produção de infográficos. Anais [Pôster] do $7^{\circ}$ Congresso Internacional de Design da Informação/Proceedings [Poster] of the 7th Information Design International Conference | CIDI 2015. São Paulo: Blucher, 2015.

PEREIRA JUNIOR, Luiz Costa. Guia para a edição jornalística. 4. Ed. - Petrópolis, RJ: Vozes, 2012.

SUZIGAN, Ana Luisa Cruz. Design e fotografia: o retrato nas capas da Revista BRAVO!. 2012. 113 f. Dissertação (Mestrado em Design) - Universidade Anhembi Morumbi, São Paulo, 2012.

TEIXEIRA, Tattiana. O futuro do presente: os desafios da Infografia jornalística. Revista Icone. V.11 n.2. 2009. 